\title{
Childhood strokes in China describing clinical characteristics, risk factors and performance indicators: a case- series study
}

\author{
Yaxian Deng (D) , ${ }^{1}$ Gaifen Liu, ${ }^{2}$ Guitao Zhang, ${ }^{3}$ Juanyu Xu, ${ }^{1}$ Chunmei Yao, ${ }^{1}$ \\ Lei Wang, ${ }^{1}$ Chengsong Zhao, ${ }^{4}$ Yongjun Wang ${ }^{3}$
}

To cite: Deng Y, Liu G, Zhang G, et al. Childhood strokes in China describing clinical characteristics, risk factors and performance indicators: a caseseries study. Stroke \& Vascular Neurology 2021;0. doi:10.1136/ svn-2021-001062

Received 14 April 2021 Accepted 9 September 2021

Check for updates

(c) Author(s) (or their employer(s)) 2021. Re-use permitted under CC BY-NC. No commercial re-use. See rights and permissions. Published by BMJ.

${ }^{1}$ Department of Pediatrics, Beijing Tiantan Hosppital Affiliated to Capital Medical University, Beijing, China

${ }^{2}$ China National Clinical

Research Center for Neurological Disease, Beijing,

China

${ }^{3}$ Department of Neurology, Beijing Tiantan Hosppital Affiliated to Capital Medical University, Beijing, China ${ }^{4}$ Outpatient Department, Beijing Children's Hospital Affiliated to Capital Medical University, Beijing, China

Correspondence to Dr Yaxian Deng; dengyx77@163.com

\section{ABSTRACT}

Aim To investigate clinical characteristics, risk factors (RFs), neurologic deficits and medical care provided in children who had a stroke in China.

Methods We conducted a retrospective case-series study using the medical records of children aged 1 month to 18 years with arterial ischaemic stroke (AIS) or haemorrhagic stroke (HS) (with the entry codes I60, I61, I62, I63 (ICD$10)$ ), who were admitted to different hospitals in Beijing, between January 2018 and December 2018. We obtained the following information from the charts: demographic characteristics, clinical presentations, RFs for paediatric stroke, laboratory examination, neuroimaging records and neurologic sequelae.

Results We identified 312 first admissions for stroke (172 AIS and $140 \mathrm{HS}$ ). The mean age at onset was $8.6 \pm 3.9$ years for patients who had an AIS and $8(5-13)$ years for patients who had an HS. There were more males than females in both groups (AIS: $59.88 \%$ vs 40.12\%; HS: $52.14 \%$ vs $47.86 \%$ ). A known aetiology was identified in $92.44 \%$ and $86.43 \%$ of patients who had an AIS and HS, respectively. The leading cause of AIS was cerebrovascular diseases including moyamoya $(68.6 \%)$, while that for HS was arteriovenous malformation (51.43\%). The most common initial clinical presentation was hemiplegia $(86.05 \%)$ in patients who had an AIS and headache $(67.86 \%)$ in patients who had an HS. The use of healthcare, including acute treatment (antithrombotic in $17.44 \%$, anticoagulant in 5.23\%) and secondary prevention (antithrombotic in $6.39 \%$, anticoagulant in $1.16 \%$ ), varied and was significantly lower among patients who had an AIS. The most common complications were epilepsy $(22.09 \%)$ and pneumonia $(4.65 \%)$ in patients who had an AIS and epilepsy (17.14\%) and hydrocephalus (12.14\%) in patients who had an HS. Neurological deficits occurred in $62.8 \%$ of patients who had an AIS and $72.86 \%$ of patients who had an HS.

Conclusion Cerebral arteriopathy was a major RF for both AIS and HS in children living in China. Large epidemiological studies are required to identify RFs to prevent stroke as well as appropriate interventions.

\section{INTRODUCTION}

Stroke is defined as a sudden-onset, focal neurologic deficit resulting from irreversible, focal, ischaemic/haemorrhagic damage to the brain parenchyma secondary to a cerebrovascular disorder. Although stroke in children is rare, with an incidence rate of 3-25 per 100 000 children per year in developed countries, it is among the top 10 causes of death in children. Stroke causes significant morbidity and mortality, which result in a larger burden on family and society. ${ }^{1-3}$ Although important similarities probably exist between stroke in young adults and that in adolescents, virtually all aspects of stroke in older adults are different from those in children. Atherosclerosis and accompanying modifiable risk factors (RFs) that dominate adult stroke mechanisms and treatment are nearly nonexistent in paediatric stroke. In the past few years, many important advances in paediatric stroke research and management have been made, offering hope of evidence-based medical advice on treatment; however, paediatricians have an insufficient level of awareness, resulting in delayed diagnosis, less experience in the use of acute antithrombotic or anticoagulant treatment and secondary prevention, including thrombolysis or thrombectomy.

The aim of this study was to provide data on the clinical presentations, RFs for paediatric stroke and to reflect the medical care situation in paediatric stroke regarding work-up and acute treatment, by reviewing the clinical data from hospitals in Beijing. To our knowledge, no multicentre study has yet assessed the clinical characteristics and the use of performance indicators in paediatric stroke in China.

\section{METHODS}

\section{Patient population}

We reviewed the charts of all inpatients between January 2018 and December 2018 with the entry codes I60, I61, I62 I63 (ICD-10, The International Statistical Classification of Diseases and Related Health Problems 10th 
Revision) from different hospitals in Beijing. All patients aged between 1 month and 18 years with a diagnosis of arterial ischaemic stroke (AIS) or haemorrhagic stroke (HS) (including intracerebral haemorrhage and subarachnoid haemorrhage) were included in our review. Exclusion criteria were (presumed) presence of perinatal/neonatal stroke, cerebral venous sinus thrombosis and transient ischaemic attack.

\section{Collected data}

For each patient, the following data were collected:

Demographics: age at admission, gender and race.

RFs: data on RFs for paediatric stroke were collected and assigned into 10 predetermined categories based on the International Pediatric Stroke Study (IPSS) definitions: arteriopathy (any arterial abnormality on vascular imaging other than isolated vessel occlusion), cardiac disorders, chronic systemic conditions, infection, acute head and neck disorders, acute systemic conditions, prothrombotic states (PTSs), chronic head and neck disorders, atherosclerosis-related RFs, other RFs and unknown.

Presentation: onset-to-door time, mode of presentation at onset including focal signs (hemiparesis, facial paralysis, visual or speech disturbance, numbness of limb, dysphagia and dizziness), diffuse signs (decreased level of consciousness and headache) and seizures.

Laboratory and auxiliary investigations: complete blood cell count, blood biochemical test, blood homocysteine, $\mathrm{C}$ reactive protein, lupus anticoagulant, anticardiolipin antibody and transthoracic echocardiogram.

Radiographic characteristics: involved vascular territory (anterior or posterior circulation or both) and laterality (unilateral or bilateral) were analysed.

Performance indicators: we selected part of the key performance indicators developed by the Get With the Guidelines-Stroke programme: (1) acute performance measures: thrombolytic therapy and early antithrombotic therapy or anticoagulant and (2) discharge performance measures: antithrombotic therapy and anticoagulation.

\section{Clinical outcomes}

The outcomes including complication, neurologic sequelae were assessed at discharge. The neurologic sequelae included movement disorder, aphasia, hearing disorder, vision deficits, cognitive disorder, feeling disorder, memory disorder and epilepsy.

\section{Statistical analysis}

Patients were categorised into four groups: infant (<1 year), preschool year (1-5 years), school year (6-12 years) and adolescent (13-18 years). Baseline characteristics including gender, age at stroke onset, RFs, presenting symptoms (focal signs, diffuse sings and epilepsy) and imaging characteristics were described in the IS and HS groups separately. The proportion of children with each RF was calculated for all children. Continuous variables were described as mean $\pm \mathrm{SD}$ if normally distributed or as
Table 1 Demographic characteristics and the presentation of children who had a stroke

\begin{tabular}{lll}
\hline & No. (\%) \\
\cline { 2 - 3 } Characteristic & AIS & HS \\
\hline Gender, male & $103(59.88)$ & $73(52.14)$ \\
Mean age at onset (years) & $8.6 \pm 3.9$ & $8.00(5.00$, \\
& & $13.00)$
\end{tabular}

Age at stroke, mean (SD)

Distribution of age (years)

\begin{tabular}{|c|c|c|}
\hline$<1$ & $2(1.16)$ & $5(3.57)$ \\
\hline $1-5$ & $40(23.26)$ & $35(25.00)$ \\
\hline $6-12$ & $99(57.56)$ & $62(44.29)$ \\
\hline $13-18$ & 31 (18.02) & $38(27.14)$ \\
\hline \multicolumn{3}{|l|}{ Mode of presentation } \\
\hline \multicolumn{3}{|l|}{ Focal signs } \\
\hline Hemiparesis & $148(86.05)$ & $43(30.71)$ \\
\hline Facial paralysis & $1(0.58)$ & $0(0)$ \\
\hline $\begin{array}{l}\text { Hemiparesis and facial } \\
\text { paralysis }\end{array}$ & $12(6.98)$ & $0(0)$ \\
\hline Speech disturbance & $43(25.29)$ & $16(11.43)$ \\
\hline Visual disturbance & $9(5.29)$ & $10(7.14)$ \\
\hline Numbness of limb & 29 (17.06) & $11(7.86)$ \\
\hline Dysphagia & $6(3.55)$ & $4(2.86)$ \\
\hline Dizziness & $12(7.02)$ & $27(19.29)$ \\
\hline \multicolumn{3}{|l|}{ Diffuse signs } \\
\hline $\begin{array}{l}\text { Decreased level of } \\
\text { consciousness }\end{array}$ & $16(9.47)$ & $43(30.71)$ \\
\hline Headache & 36 (21.18) & $95(67.86)$ \\
\hline Seizures & 29 (17.16) & $24(17.14)$ \\
\hline \multicolumn{3}{|l|}{ Laterality (only AIS) } \\
\hline Unilateral & 117 (68.02) & - \\
\hline Bilateral & $44(25.58)$ & - \\
\hline
\end{tabular}

AIS, arterial ischaemic stroke.

median and IQR if it is not normally distributed. Categorical variables are presented as absolute numbers with percentages. Statistical analysis was performed using a commercially available software package (SPSS V.19.0).

\section{RESULTS}

\section{Population characteristics}

In total, 312 patients were included; 172 patients $(55.1 \%$ of the whole series) had AIS and $140(44.9 \%)$ had HS. Demographic characteristics and clinical presentation of children who had an AIS or HS (including mean age at stroke onset, sex ratio, distribution of age and mode of presentation) are shown in table 1. For AIS, the peak distribution ages were between $1-5$ years and $6-12$ years and 103 children were males (M:F=1.49). For HS, the peak distribution ages were between 6-12 years and 13-18 years; 73 children were males (M:F=1.09). 


\section{Presenting symptoms}

Table 1 shows the presenting symptoms for all patients who had an AIS and HS. Focal symptoms, in particular acute hemiparesis, including facial paralysis, were the most common presenting symptoms in patients who had an AIS. Non-specific symptoms, such as headache and decreased level of consciousness, were observed in $21.18 \%$ and $9.47 \%$ of the patients, respectively; $17.16 \%$ children presented with seizures. For HS, non-specific symptoms such as headache and decreased level of consciousness were the most common presenting features. The rate of seizures in patients who had an AIS was similar to that in patients who had an HS. Bilateral ischaemia occurs in $26.58 \%$ patients.

\section{Aetiologies and RFs}

A known RF was identified in $92.44 \%$ and $86.43 \%$ of patients who had an AIS and HS. The leading causes were arteriopathies including moyamoya (118 patients) and dissection (5 patients) for AIS and arteriovenous malformation (AVM) and cavernous malformation (CM) for HS. Cardiac diseases only occurred in 14 patients. A detailed overview of the described RFs is shown in table 2.

We analysed the proportion of patients according to age, clinical presentations, gender and dysfunction after stroke in patients who had an AIS resulting from moyamoya and in those who had an HS resulting from AVM or CM (figure 1). We also analysed the proportion of RFs, clinical presentation and neurological deficits according to different age groups (figure 2).

\section{Performance indicators and complications}

None of the patients received hyperacute therapy (thrombolysis or mechanical thrombectomy). Diagnostic work-ups in hypertension, hyperlipidemia and diabetes were rarely applied. Among patients who had an AIS, the proportions of those who used antithrombotic and anticoagulation use were $17.44 \%$ and $5.23 \%$, respectively. Additionally, among patients who had an AIS, aspirin was administered at discharge in $5.23 \%$ patients, clopidogrel in $1.16 \%$ patients and warfarin in $1.16 \%$ patients. Epilepsy was the most common complication in both the ischaemic and HS groups. Neurological deficits occurred in $62.8 \%$ of patients who had an AIS and $72.86 \%$ of patients who had an HS. Performance indicators, complications on discharge and neurologic deficits in patients who had an AIS or HS are shown in table 3.

\section{DISCUSSION}

Paediatric stroke is a severe condition, with potentially devastating consequences such as development (motor, language and mentality) and behavioural disabilities or epilepsy. ${ }^{4}$ Awareness about initial symptoms, using MRI first and adapted management in the acute phase, individualised thrombolysis or recanalisation treatment strategies, antithrombotic and anticoagulation therapy are the key elements to improve paediatric management and outcomes. ${ }^{5}$
Our study provides multicentre data of children who had an AIS and HS and to some extent reflected the current medical care situation in paediatric stroke in China. The result regarding sex ratio was similar to that reported in the literature. ${ }^{6}$ Both ischaemic stroke and HS were more common among males than among females. ${ }^{6}$ The most common presenting symptom among patients who had an AIS was acute focal neurological deficit, which was consistent with the literature reports. ${ }^{6}$ Seizures occurred in $17.16 \%$ cases, which was consistent with Silverman and Zelano's ${ }^{78}$ reports that poststroke seizures occurred in 5\%-20\%, but lower than Polat et al's ${ }^{9}$ report (59\% patients).

Regarding RFs, in our study, arteriopathy (85.47\%) and cardiac diseases $(8.14 \%)$ were the most common RFs for AIS. The ratio of RF of cerebral arteriopathy for AIS was higher than that in some researches. However, recent studies have also reported that children arteriopathy was the most common identifiable cause of AIS, accounting for up to $60 \%-80 \%$ of cases in previously healthy children, and it was reported to be the strongest predictor of recurrent events. ${ }^{10}$ In a previous study, the most common causes of intracranial arterial steno-occlusive disease in children were ${ }^{12}$ and this finding is consistent with that of our study. Traumatic craniocervical arterial dissection, especially carotid artery dissection, was a common cause of cerebrovascular injuries in children, accounting for approximately $20 \%$ of paediatric acute ischaemic strokes which was higher than that reported in our study $(2.91 \%) .{ }^{13}$ In children presenting with posterior circulations strokes, dissection of the vertebral artery should always be considered in the differential consideration. ${ }^{14}$ Data from the IPSS showed that cardiac diseases are the primary cause of AIS, accounting for $28 \%{ }^{15}$ which was higher than our result $(8.14 \%)$. PTSs were not found in our cases. However, the literature reported that thromboembolic causes accounted for $20 \%-30 \%$ of causes of paediatric AIS. ${ }^{5}$ The low ratio may be related to insufficient haematological examination in our cases. Several recommendations have been published concerning aetiological work-up in paediatric AIS and the authors proposed the following investigations: comprehensive clinical evaluation, haematological investigations, biochemistry tests, thrombophilia testing, inflammation and infection tests and cardiovascular evaluation. ${ }^{16}$ RFs for HS were mainly AVM and CM and this result is consistent with previous reports. $^{1718}$

The time delay in onset-to-door time, door-to-imaging time and door-to-needle time is a well-known barrier in paediatric stroke care, which may prevent time-critical treatments such as thrombolysis or mechanical thrombectomy. ${ }^{19}$ In our cohort, onset-to-door time was significantly prolonged. Onset-to-door time of less than 24 hours was observed in $14.4 \%$ of patients who had an HS and in $3.7 \%$ of patients who had an AIS. Onset-to-door time delay in our patients may be related to the aetiologies, as AIS was more likely to be caused by moyamoya in our study. Although, several studies have shown that 
Table 2 Risk factors (RFs) of patients who had an AIS and HS

\begin{tabular}{|c|c|c|c|c|}
\hline \multirow[b]{2}{*}{ RFs } & \multicolumn{2}{|l|}{ AIS } & \multicolumn{2}{|l|}{ HS } \\
\hline & Number & Per cent & Number & Per cent \\
\hline Arteriopathy & & & 140 & \\
\hline Moyamoya & 118 & 68.60 & 8 & 5.71 \\
\hline Dissection & 5 & 2.91 & 1 & 0.71 \\
\hline Vasculitis & 7 & 4.07 & 2 & 1.43 \\
\hline PVA & 1 & 0.58 & 0 & 0 \\
\hline Peripheral vascular disease & 1 & 0.58 & 0 & 0 \\
\hline AVM & 0 & 0 & 72 & 51.43 \\
\hline $\mathrm{CM}$ & 0 & 0 & 28 & 20.00 \\
\hline Aneurysm & 0 & 0 & 6 & 4.29 \\
\hline AVF & 0 & 0 & 3 & 2.14 \\
\hline Venous malformation of scalp & 0 & 0 & 0 & 0 \\
\hline Angiotelectasis & 1 & 0.58 & 0 & 0 \\
\hline \multicolumn{5}{|l|}{ Cardiac disorders } \\
\hline ASD & 1 & 0.58 & 0 & 0 \\
\hline VSD & 2 & 1.16 & 0 & 0 \\
\hline RHD & 1 & 0.58 & 1 & 0.71 \\
\hline Arrhythmia & 2 & 1.16 & 0 & 0 \\
\hline Hypertension & 2 & 1.16 & 4 & 2.86 \\
\hline $\mathrm{KD}$ & 1 & 0.58 & 0 & \\
\hline PDA & 1 & 0.58 & 1 & 0.71 \\
\hline Endocarditis & 1 & 0.58 & 1 & 0.71 \\
\hline DCM & 1 & 0.58 & 0 & 0 \\
\hline PFO & 1 & 0.58 & 0 & 0 \\
\hline Pulmonary artery stenosis & 1 & 0.58 & 0 & 0 \\
\hline \multicolumn{5}{|l|}{ Chronic head and neck disorders } \\
\hline Cerebral tumour & 2 & 1.16 & 4 & 2.86 \\
\hline Ventriculoperitoneal shunt & 0 & 0 & 1 & 0.71 \\
\hline Sturge-Weber syndrome & 0 & 0 & 0 & 0 \\
\hline \multicolumn{5}{|l|}{ Acute head and neck disorders } \\
\hline Nasosinusitis & 9 & 5.23 & 0 & 0 \\
\hline Mastoiditis & 1 & 0.58 & 0 & 0 \\
\hline Brain trauma & 4 & 2.33 & 3 & 2.14 \\
\hline \multicolumn{5}{|l|}{ Chronic systemic conditions } \\
\hline Connective tissue disease & 3 & 1.74 & 0 & 0 \\
\hline Iron-deficiency anaemia & 1 & 0.58 & 0 & 0 \\
\hline Down syndrome & 1 & 0.58 & 0 & 0 \\
\hline MELAS & 5 & 2.91 & 0 & 0 \\
\hline Prothrombotic states & 0 & 0 & 0 & 0 \\
\hline Acute systemic conditions & - & - & - & - \\
\hline Fever $>48$ hours & 1 & 0.58 & 1 & 0.71 \\
\hline Unknown & 13 & 7.56 & 19 & 13.57 \\
\hline
\end{tabular}

AIS, arterial ischaemic stroke; ASD, atrial septal defect; AVF, arteriovenous fistula; AVM, arteriovenous malformation; CM, cavernous malformation; DCM, dilated cardiomyopathy; HS, haemorrhagic stroke; KD, Kawasaki disease; MELAS, mitochondrial encephalopathy with lactic acidosis and stroke-like episodes; PDA, patent ductus arteriosus; PFO, patent foramen ovale; PVA, postvaricella arteriopathy; RHD, rheumatic heart disease; VSD, ventricular septal defect. 


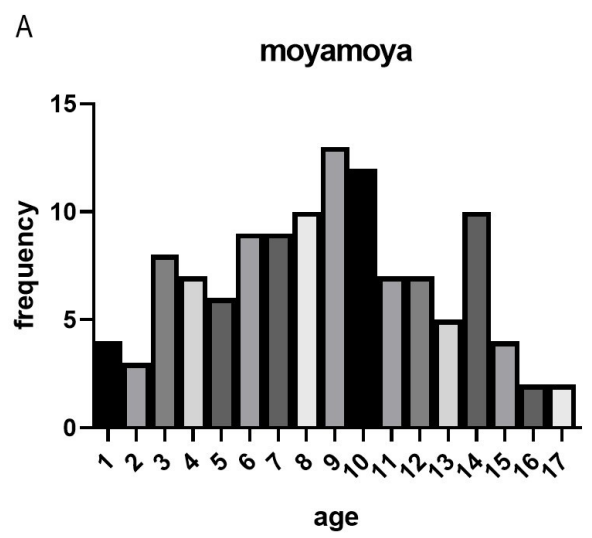

C
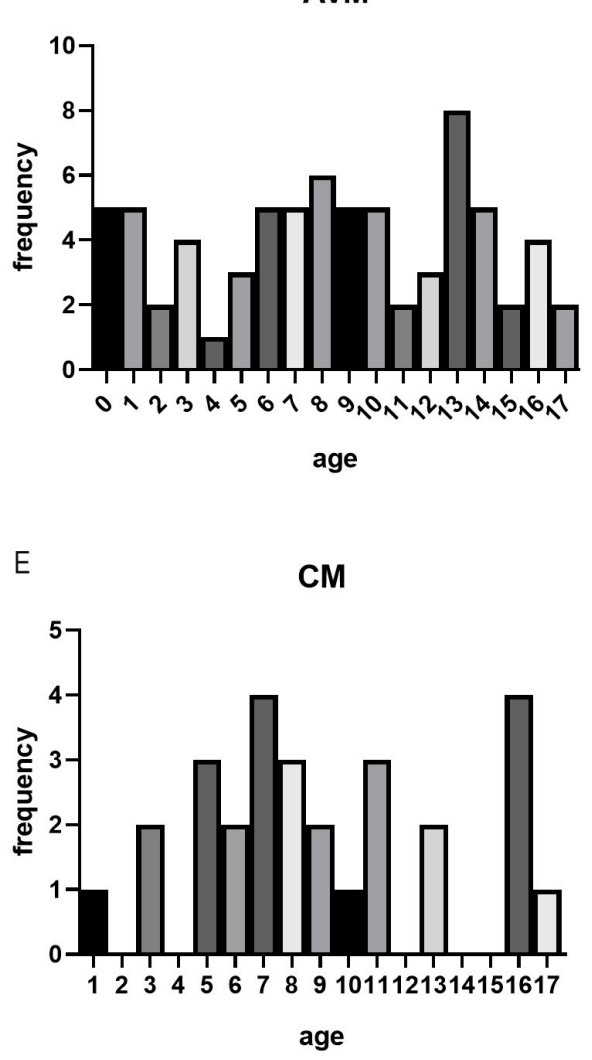

B

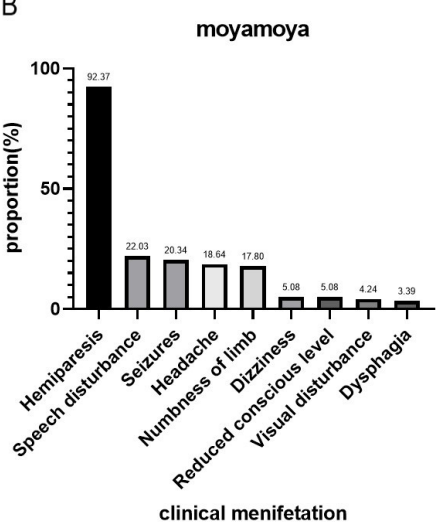

D

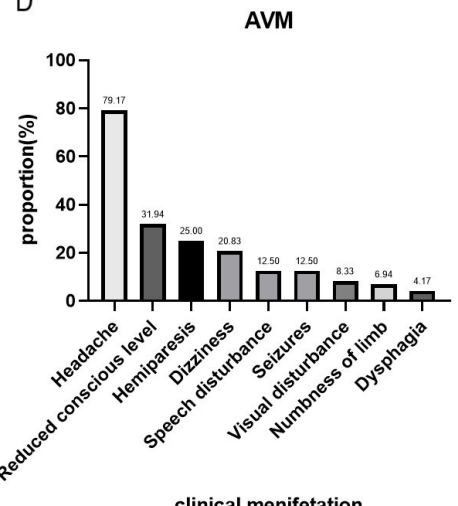

clinical menifetation

$\mathrm{F}$

CM

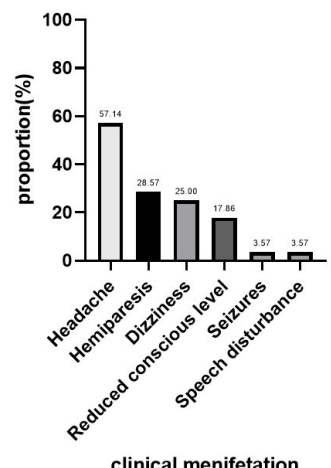

clinical menifetation

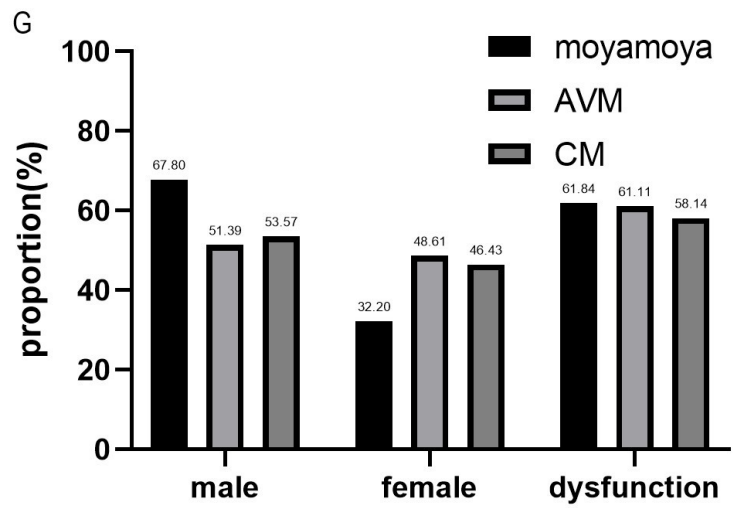

Figure 1 Proportion of age, clinical presentation, gender and dysfunction after stroke in AIS resulting from moyamoya ( A, B and $\mathrm{G}), \mathrm{HS}$ resulting from $\mathrm{AVM}(\mathrm{C}, \mathrm{D}$ and $\mathrm{G})$ or $\mathrm{CM}(\mathrm{E}, \mathrm{F}$ and $\mathrm{G})$. 

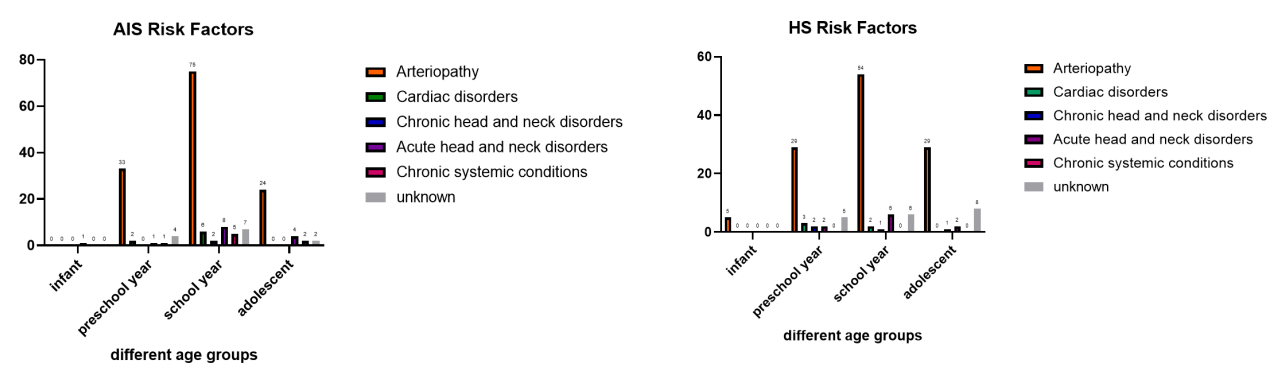

endovascular clot retrieval and thrombolysis in adult stroke and in some children have excellent results. ${ }^{20-29} \mathrm{In}$ our study, no thrombolysis or mechanical thrombectomy was used and antithrombotic and anticoagulation use was only observed in $17.44 \%$ and $5.23 \%$ of patients who had an AIS. The low rate of thrombolysis and antithrombotic use may be related to delayed hospital visit and delayed diagnosis. Moreover, the lack of awareness for paediatric stroke, more stroke-mimicking diseases as well as insufficient paediatric stroke attention may be mainly responsible for this unsatisfactory situation. In order to decrease time of onset to diagnosis and decision making, apart from increasing awareness, there should be considerable effort invested into improving clinical pathways including establishment of paediatric acute stroke centres and standardised protocol for evaluation and treatment of stroke.

In recent years, some methods of evaluation and classification of ischaemic stroke in children have been developed such as modified paediatric version of the Alberta Stroke Program Early CT Score using acute MRI, ${ }^{30}$ the Childhood AIS Standardized Classification And Diagnostic Evaluation criteria ${ }^{31}$ and the paediatric version of the National Institutes of Health Stroke Scale ${ }^{32}$; however, these methods are not universally used. American College of Chest Physicians Evidence-Based Clinical Practice Guidelines and the American Heart Association Stroke Council and the Council on Cardiovascular Disease have also developed an expert consensus on the diagnosis and treatment of stroke in children ${ }^{33} 34$; however, it has not been effectively applied to clinical treatment.

In terms of long-term outcomes, children and young people do not necessarily recover better than adults 
Table 3 Examination, performance indicators and complications on discharge of patients who had an AIS and HS

\begin{tabular}{|c|c|c|c|c|}
\hline \multirow[b]{2}{*}{ Indicators } & \multicolumn{2}{|l|}{ AS } & \multicolumn{2}{|l|}{ HS } \\
\hline & Number & Per cent & Number & Per cent \\
\hline TTE examination & 57 & 33.14 & 13 & 9.29 \\
\hline Bubble study & 5 & 2.91 & 0 & 0 \\
\hline Positive bubble study & $2 / 5$ & 40.00 & 0 & 0 \\
\hline MRI examination of the brain & 162 & 94.19 & 125 & 89.29 \\
\hline MRA examination of the brain & 64 & 37.21 & 14 & 8.57 \\
\hline CTA of the head & 77 & 44.77 & 18 & 10.00 \\
\hline DSA of the head & 125 & 52.90 & 83 & 59.28 \\
\hline Antithrombotic & 30 & 17.44 & - & - \\
\hline Anticoagulant & 9 & 5.23 & - & - \\
\hline Neuroprotective agents & 50 & 29.07 & 22 & 15.71 \\
\hline Antiepileptic drug & 93 & 54.07 & 53 & 37.86 \\
\hline \multicolumn{5}{|l|}{ Discharge medication } \\
\hline \multicolumn{5}{|l|}{ Antithrombotic } \\
\hline Aspirin & 9 & 5.23 & - & - \\
\hline Clopidogrel & 2 & 1.16 & - & - \\
\hline \multicolumn{5}{|l|}{ Anticoagulant } \\
\hline \multicolumn{5}{|l|}{ Complication } \\
\hline Pneumonia & 8 & 4.65 & 13 & 9.29 \\
\hline Cerebral hernia & 0 & 0 & 3 & 2.14 \\
\hline Infection of CNS & 2 & 1.16 & 6 & 4.29 \\
\hline Electrolyte disturbance & 1 & 0.58 & 13 & 9.29 \\
\hline \multicolumn{5}{|l|}{ Neurological deficits } \\
\hline Movement & 77 & 44.77 & 59 & 42.14 \\
\hline Speech & 13 & 7.56 & 11 & \\
\hline hearing & 1 & 0.58 & 1 & 0.71 \\
\hline Vision & 4 & 2.33 & 4 & 2.86 \\
\hline Cognitive & 5 & 2.91 & 2 & 1.43 \\
\hline Epilepsy & 38 & 22.09 & 24 & 17.14 \\
\hline Feelling & 1 & 0.58 & 1 & 0.71 \\
\hline Memory & 0 & 0 & 0 & 0 \\
\hline
\end{tabular}

AIS, arterial ischaemic stroke; CNS, central nervous system; CTA, computed tomographic angiography; DSA, digital angiography; HS, haemorrhagic stroke; MRA, magnetic resonance angiography; TCD, transcranial Doppler; TTE, transthoracic echocardiogram.

from stroke. Mosch et a $\hat{l}^{35}$ demonstrated that children and adults matched for infarct site had similar levels of impairment. Pavlovic et al reported that up to two-thirds of patients experience lifelong neurological or cognitive sequelae. ${ }^{15}{ }^{36}$ Hemiparesis is one of the most common long-term neurological consequences. It has been reported in over half of the children in a previous study. ${ }^{37}$ However, there are few outcome measure assessment 
tools for paediatric stroke. The paediatric stroke outcome measure is a standardised neurological examination/ impairment level assessment tool, specifically validated in infants ( $\leq 2$ years of age) and in children and young people (2-16years) who had an AIS. Outcomes are highly variable with regard to the field of outcomes tested and aetiology of stroke. Data from the IPSS including more than 600 children who had an AIS reported residual impairments in $74 \%$ of them. ${ }^{38}$ Most studies estimate that over $50 \%-70 \%$ of patients who had a paediatric stroke will have long-lasting or persistent neurological deficits or develop subsequent cognitive, learning, seizure disorders or developmental problems. ${ }^{1539}$

\section{Strength and limitations of the study}

There are some advantages of the study design. First is the multicentre design and the relatively large sample size. Second, recruiting patients from different hospitals may improve the generalisability to some extent compared with single-centre study. There are a few limitations to the study. First, only several hospitals were included in the study and there maybe inclusion bias. Second, the study was retrospective and the data may be incomplete.

\section{CONCLUSION}

Arteriopathy was the most common RF in patients who had an AIS, accounting for $85.47 \%$, while cardiac diseases were seldom reported and prothrombotic state was not observed in our study as RFs. AVM and CM were the most common causes of HS. The use of healthcare was significantly lower in all patients who had an AIS including acute treatment and discharge medication use. Ultimately, large epidemiological studies are required to identify RFs to prevent stroke as well as appropriate interventions.

Acknowledgements The authors thank all participating colleagues for their contribution to this study.

Contributors YW and CZ had substantial contributions to the conception or design of the work. YD drafted the article, revised it critically for important intellectual content and was responsible for the final approval of the version to be published. GZ was responsible for statistical analysis. JX, CY and LW were responsible for the collection of the data.

Funding The authors have not declared a specific grant for this research from any funding agency in the public, commercial or not-for-profit sectors.

Competing interests None declared.

Patient consent for publication Not applicable.

Ethics approval The study obtained ethics approval from Tiantan Institutional Review Board (IRB) (IRB approval number KY 2018-081-02). This study was a retrospective case-series study and does not reveal any personal privacy, so patient's informed consent could not be obtained, but the authors strictly abide by theDeclaration of Helsinki.

Provenance and peer review Not commissioned; externally peer reviewed. Data availability statement All data relevant to the study are included in the article or uploaded as supplementary information.

Open access This is an open access article distributed in accordance with the Creative Commons Attribution Non Commercial (CC BY-NC 4.0) license, which permits others to distribute, remix, adapt, build upon this work non-commercially, and license their derivative works on different terms, provided the original work is properly cited, appropriate credit is given, any changes made indicated, and the use is non-commercial. See: http://creativecommons.org/licenses/by-nc/4.0/.
ORCID iD

Yaxian Deng http://orcid.org/0000-0002-9152-316X

\section{REFERENCES}

1 Darteyre S, Chabrier S, Presles E, et al. Lack of progressive arteriopathy and stroke recurrence among children with cryptogenic stroke. Neurology 2012;79:2342-8.

2 Lehman LL, Maletsky K, Beaute J, et al. Prevalence of symptoms of anxiety, depression, and post-traumatic stress disorder in parents and children following pediatric stroke. J Child Neurol 2020;35:472-9.

3 Sacco RL, Kasner SE, Broderick JP, et al. An updated definition of stroke for the 21st century: a statement for healthcare professionals from the American heart association/american stroke association. Stroke 2013;44:2064-89.

4 Mallick AA, Ganesan V, Kirkham FJ, et al. Outcome and recurrence 1 year after pediatric arterial ischemic stroke in a population-based cohort. Ann Neurol 2016;79:784-93.

5 Kossorotoff M, Chabrier S, Tran Dong K, et al. Arterial ischemic stroke in non-neonate children: diagnostic and therapeutic specificities. Rev Neurol 2020;176:20-9.

6 Gerstl L, Weinberger R, Heinen F, et al. Arterial ischemic stroke in infants, children, and adolescents: results of a Germany-wide surveillance study 2015-2017. J Neurol 2019;266:2929-41.

7 Zelano J. Poststroke epilepsy: update and future directions. Ther Adv Neurol Disord 2016;9:424-35.

8 Silverman IE, Restrepo L, Mathews GC. Poststroke seizures. Arch Neurol 2002;59:195-201.

9 Polat İpek, Yiș U, Ayanoğlu M, et al. Risk factors of post-stroke epilepsy in children; experience from a tertiary center and a brief review of the literature. J Stroke Cerebrovasc Dis 2021;30:105438.

10 Amlie-Lefond C, Wainwright MS. Organizing for acute arterial ischemic stroke in children. Stroke 2019;50:3662-8.

11 Fullerton $\mathrm{HJ}$, Wintermark M, Hills NK, et al. Risk of recurrent arterial ischemic stroke in childhood: a prospective international study. Stroke 2016;47:53-9.

12 Wintermark M, Hills NK, DeVeber GA, et al. Clinical and imaging characteristics of arteriopathy subtypes in children with arterial ischemic stroke: results of the vips study. AJNR Am J Neuroradiol 2017;38:2172-9.

13 Oelerich M, Stögbauer F, Kurlemann G, et al. Craniocervical artery dissection: MR imaging and MR angiographic findings. Eur Radiol 1999;9:1385-91.

14 McCrea N, Saunders D, Bagkeris E, et al. Diagnosis of vertebral artery dissection in childhood posterior circulation arterial ischaemic stroke. Dev Med Child Neurol 2016;58:63-9.

15 Chung MG, Guilliams KP, Wilson JL, et al. Arterial ischemic stroke secondary to cardiac disease in neonates and children. Pediatr Neurol 2019;100:35-41.

16 Medley TL, Miteff C, Andrews I, et al. Australian clinical consensus guideline: the diagnosis and acute management of childhood stroke. International Journal of Stroke 2019;14:94-106.

17 Fullerton HJ, Wu YW, Sidney S, et al. Risk of recurrent childhood arterial ischemic stroke in a population-based cohort: the importance of cerebrovascular imaging. Pediatrics 2007;119:495-501.

18 Beslow LA, Licht DJ, Smith SE, et al. Predictors of outcome in childhood intracerebral hemorrhage: a prospective consecutive cohort study. Stroke 2010;41:313-8.

19 Mallick AA, Ganesan V, Kirkham FJ, et al. Diagnostic delays in paediatric stroke. J Neurol Neurosurg Psychiatry 2015;86:917-21.

20 Bigi S, Dulcey A, Gralla J, et al. Feasibility, safety, and outcome of recanalization treatment in childhood stroke. Ann Neurol 2018;83:1125-32.

21 Sun LR, Felling RJ, Pearl MS. Endovascular mechanical thrombectomy for acute stroke in young children. $J$ Neurointerv Surg 2019;11:554-8.

22 Rennie A. Endovascular clot retrieval for acute ischaemic posterior circulation stroke in children: a new effective therapy? Dev Med Child Neurol 2020;62:1119-20.

23 Jiménez Gómez E, Bravo Rey I, Oteros Fernández R, et al. Endovascular treatment of stroke in children under 2 years with heart failure and ventricular assist device. Interventional Neuroradiology 2019;25:516-20.

24 van Es ACGM, Hunfeld MAW, van den Wijngaard I, et al. Endovascular treatment for acute ischemic stroke in children: experience from the MR clean registry. Stroke 2021;52:781-8.

25 Ferriero DM, Fullerton HJ, Bernard TJ, et al. Management of stroke in neonates and children: a scientific statement from the 
American heart association/american stroke association. Stroke 2019;50:e51-96.

26 Wang M, Hays T, Balasa V, et al. Low-dose tissue plasminogen activator thrombolysis in children. $J$ Pediatr Hematol Oncol 2003;25:379-86.

27 Sporns PB, Wildgruber M, Kemmling A. Letter by sporns et al regarding article, "Organizing for acute arterial ischemic stroke in children". Stroke 2020;51:e36.

28 Sun LR, Harrar D, Drocton G, et al. Mechanical thrombectomy for acute ischemic stroke: considerations in children. Stroke 2020;51:3174-81.

29 Cappellari M, Moretto G, Grazioli A, et al. Primary versus secondary mechanical thrombectomy for anterior circulation stroke in children: an update. J Neuroradiol 2018;45:102-7.

30 Beslow LA, Kasner SE, Smith SE, et al. Concurrent validity and reliability of retrospective scoring of the pediatric National Institutes of health stroke scale. Stroke 2012;43:341-5.

31 Bernard TJ, Manco-Johnson MJ, Lo W, et al. Towards a consensusbased classification of childhood arterial ischemic stroke. Stroke 2012;43:371-7.

32 Ichord RN, Bastian R, Abraham L, et al. Interrater reliability of the pediatric National Institutes of health stroke scale (PedNIHSS) in a multicenter study. Stroke 2011;42:613-7.

33 Monagle P, Chalmers E, Chan A, et al. Antithrombotic therapy in neonates and children: American College of chest physicians evidence-based clinical practice guidelines (8th edition). Chest 2008;133:887S-968.

34 Roach ES, Golomb MR, Adams R, et al. Management of stroke in infants and children: a scientific statement from a special writing group of the American heart association stroke Council and the Council on cardiovascular disease in the young. Stroke 2008;39:2644-91.

35 Mosch SC, Max JE, Tranel D. A matched lesion analysis of childhood versus adult-onset brain injury due to unilateral stroke: another perspective on neural plasticity and recovery of social functioning. Cogn Behav Neurol 2005;18:5-17.

36 Pavlovic J, Kaufmann F, Boltshauser E, et al. Neuropsychological problems after paediatric stroke: two year follow-up of Swiss children. Neuropediatrics 2006;37:13-19.

37 Goeggel Simonetti B, Cavelti A, Arnold M, et al. Long-Term outcome after arterial ischemic stroke in children and young adults. Neurology 2015;84:1941-7.

38 Goldenberg NA, Bernard TJ, Fullerton HJ, et al. Antithrombotic treatments, outcomes, and prognostic factors in acute childhoodonset arterial ischaemic stroke: a multicentre, observational, cohort study. Lancet Neurol 2009;8:1120-7.

39 Ganesan V, Hogan A, Shack N, et al. Outcome after ischaemic stroke in childhood. Dev Med Child Neurol 2000;42:455-61. 